\title{
SISTEMAS DE CULTIVO E CUSTOS DE PRODUÇÃO DE Thuja occidentalis L. E Thuja orientalis L. EM QUATRO MUNICÍPIOS DO ESTADO DO RIO GRANDE DO SUL
}

\author{
Diego Martins Stangerlin ${ }^{1}$, Rafael Rodolfo de Melo ${ }^{1}$, Cristiane Roppa ${ }^{2}$, Daniela Silva \\ Lilge ${ }^{1}$
}

(recebido em 28.02.2008 e aceito para publicação em 20.06.2008)

\section{RESUMO}

Objetivou-se avaliar os sistemas de cultivo e os custos de produção de Thuja occidentalis L. e Thuja orientalis L.. O levantamento dos dados foi realizado em quatro municípios do Estado do Rio Grande do Sul. Foi constatada a preferência de multiplicação por estacas de $T$. occidentalis e por sementes de $T$. orientalis. Em relação às mudas cultivadas a campo, essas permanecem no campo de dois a quatro anos, quando são transplantadas para vasos. Já para o cultivo em vasos, as mudas são cultivadas em sacos de plástico e transplantadas para vasos, exigindo mais experiência dos viveiristas para que não ocorra enovelamento das raízes. O custo total médio da muda propagada por semente é de $R \$$ 2,77 para mudas de até um ano de idade e $R \$ 2,79$ para a muda propagada por estaquia. sistema de cultivo a campo foi o que demonstrou maior produtividade. Já a taxa de desenvolvimento das mudas foi maior nos sistemas que utilizam propagação por semente. Thuja occidentalis apresentaram maior sobrevivência quando propagadas por estacas e cultivadas a campo, enquanto que Thuja orientalis quando propagadas por sementes e em vasos.

Palavras-chave: Sistemas de cultivo, custos de produção, Thuja occidentalis e Thuja orientalis, Rio Grande do Sul.

\footnotetext{
${ }^{1}$ Engenheiros Florestais, Mestrandos, Programa de Pós-Graduação em Engenharia Florestal, Universidade Federal de Santa Maria (UFSM), Santa Maria, RS, <diego_stangerlin@yahoo.com.br>

${ }^{2}$ Engenheira Florestal, Mestranda, Programa de Pós-Graduação em Ciências Florestais e Ambientais, Universidade Federal Rural do Rio de Janeiro (UFRRJ), Seropédica, RJ
} 


\title{
CULTIVATION SYSTEMS AND PRODUCTION COSTS OF Thuja occidentalis L. AND Thuja orientalis L. IN RIO GRANDE DO SUL STATE, BRAZIL
}

\begin{abstract}
This work has objective to determine artificial cultivation systems and production costs of Thuja occidentalis L. and Thuja orientalis L.. The data survey was done in four counties in Rio Grande do Sul State. It was verified a preference for stems propagation of Thuja occidentalis and for seeds of Thuja orientalis. Due to cultivated seedlings, they remain on the field during two to four years, when they are transferred to vases. The seedlings cultivated in plastic bags and transferred to vases, demanding more experience from nursery workers. The average total cost by seedling is $\mathrm{R} \$ 2.77$ for one year-old seedling, while total average cost by stems propagation is $R \$ 2.79$. Between two cultivation systems, field cultivation is the one with higher production cost. It was concluded that development from the seedlings is better in systems with seedlings than stems propagation; Thuja occidentalis seedlings showed higher surviving tax when propagated by stems and cultivated in the field, but Thuja orientalis seedlings showed higher surviving tax when propagated by roots in vases.
\end{abstract}

Key-words: Cultivation systems, production costs, Thuja occidentalis, Thuja orientalis and Rio Grande do Sul. 


\section{INTRODUÇÃO}

A produção de mudas em viveiros, segundo Martins et al. (1998), constitui a primeira etapa da atividade florestal e pode ser feita por meio da propagação por sementes ou vegetativa. Essa atividade é realizada visando a maximização dos lucros, redução dos custos e otimização da produção.

Quer seja na arborização urbana ou em jardins particulares, busca-se introduzir espécies arbóreas ou arbustivas adequadas, aliadas com padrões de beleza e qualidade. Espécies de singular beleza são fundamentais para a transformação da paisagem em um lugar deslumbrante e acolhedor, para que suas características positivas possam ser expressas e permaneçam ao longo de seu ciclo é indispensável mudas de boa qualidade (Grey \& Deneke, 1978; Miller, 1997).

As árvores com sua diversidade de formas, cores e aromas, identificam locais e qualificam espaços, proporcionando um caráter plástico á paisagem e proporcionam maior conforto ambiental (Santos \& Teixeira, 2001). O gênero Thuja é de origem exótica, pertencente à família Cupressaceae e compreende cinco espécies. Caracteriza-se pela disposição dos ramos em planos horizontais ou verticais e por ter folhas escamiformes oposto-cruzadas, apresentando cones formados por 8 ou mais escamas, com 1 a 3 óvulos cada um (Marchiori, 1996). O gênero Thuja é amplamente cultivado no Brasil, merecendo destaque em projetos de paisagismo. As principais espécies cultivadas são T. occidentalis e $T$. orientalis, as quais geralmente são multiplicadas por sementes.

T. occidentalis é originária do sul do Canadá e nordeste dos Estados Unidos, onde é conhecida como "northern white cedar" ou "arbor vitae" (árvore da vida). É uma árvore monóica, que possui de 15 a $20 \mathrm{~m}$ de altura e $90 \mathrm{~cm}$ de diâmetro, de copa piramidal. Não tolera solos secos e prefere solos profundos, com pH de 5,2 a 7,0. Apresenta casca marrom alaranjada, que se torna marrom escura e provida de sulcos longitudinais na idade adulta. Possui ramos horizontais, voltados para cima na porção terminal. As folhas são escamiformes e verde-escuras, providas de glândulas de óleo com formato cônico, especialmente nos ramos centrais. Seus cones masculinos, de forma globosa, terminais, amarelos e constituídos por 3 pares de folhas polínicas. Os cones femininos, oblongos e de cor marrom clara e até $10 \mathrm{~mm}$ de diâmetro. As sementes, de pequeno tamanho (2,5 a 3,5 mm), são providas de asa marginal (Marchiori, 1996).

Também a madeira de $T$. occidentalis $\mathrm{L}$. é de boa qualidade e pode ser usada para os mais variados fins. A árvore possui características ornamentais notáveis, sendo recomendada como planta isolada, em grupos e para formar cercas vivas (Lorenzi et al., 2003). Sua produção no Brasil, contudo, ainda é voltada quase que exclusivamente para o 
âmbito ornamental, tendo em vista sua alta tolerância à poda em qualquer época do ano. A cultura popular ainda indica seu uso como planta medicinal.

$T$. orientalis L. é uma árvore originária da China e Ásia Oriental, aprecia clima frio e apresenta crescimento lento. Seu porte vai de 9 a 12 metros; possui ramagem densa, ramos eretos dispostos em planos verticais, folhas pequenas, triangulares, sulcadas nas costas, verdes em ambas as superfícies, com leve aroma quando esfregadas, comprimidas na ramagem nova, às vezes com diversos troncos a partir da base, ocasionalmente colunas. As flores masculinas e femininas encontram-se separadas na mesma planta (monóica); masculinas de cor amarela e as femininas formam frutos (cones) ovóides, carnosos, verdeazulados quando novos, com 6 - 8 escamas lenhosas, no amadurecimento com uma saliência em gancho perto do ápice. É amplamente utilizada para paisagismo nas Regiões Sul e Sudeste do Brasil, tanto isoladamente, como em grupos para formando cercas-vivas ou quebra-ventos (Lorenzi et al., 2003).

A reprodução da Thuja é uma etapa que exigem cuidados. As mudas são formadas por estaquia ou por sementes, diretamente a campo, podendo também ser cultivadas em vasos (Glass, 2001). Segundo Macedo (1993) e Carneiro (1995), a escolha do tipo de recipiente também é importante, podendo ser utilizado em função do seu custo de aquisição, das vantagens na operação (durabilidade, possibilidade de reaproveitamento, área ocupada no viveiro, facilidade de movimentação e transporte etc) e de suas características para a formação de mudas de boa qualidade.

Este trabalho teve por objetivos avaliar os sistemas de cultivo e os custos de produção de Thuja occidentalis e Thuja orientalis em quatro municípios do Estado do Rio Grande do Sul.

\section{MATERIAIS E MÉTODOS}

A obtenção dos dados referentes aos sistemas de cultivo, custos e desenvolvimento das plantas foi realizada a partir de visitas técnicas aos viveiros e pequenos produtores rurais. Foram entrevistados seis produtores de diferentes municípios do Estado do Rio Grande do Sul em viveiros, um localizado em Santa Maria pertencente à Fepagro Florestas (Fundação Estadual de Pesquisas Agropecuárias do Rio Grande do Sul); dois em Santo Cristo; outros dois de Montenegro e um de Nova Petrópolis. Os viveiros entrevistados foram selecionados em razão de serem os únicos do Estado que produzem tuias comercialmente (Tabela 1).

Nos dados relativos aos custos, foram incluídos os custos fixos e variáveis. Dentre os variáveis foram avaliados os custos de insumos, gastos com luz, água e transporte. Já os fixos, foram avaliados gastos com implementos, maquinário e mão-de-obra. Neste caso, 
foram listados os materiais necessários (insumos e implementos) para produção da mudas de Thuja, os quais posteriormente tiveram seus preços pesquisados no comércio das regiões em estudo. Tanto para os insumos, como para os implementos utilizados na produção, foi considerado o valor médio dos preços obtidos entre os diferentes locais pesquisados.

Tabela 1. Lista utilizada na entrevista realizada com os produtores de Thuja.

\begin{tabular}{cl}
\hline Sistema de cultivo a campo & \\
\hline \multirow{3}{*}{ Por sementes } & Principais características? \\
\cline { 2 - 2 } & Aspectos positivos? \\
\cline { 2 - 2 } Por estacas & Principais características? \\
\cline { 2 - 2 } & Aspectos positivos? \\
\cline { 2 - 2 } Sistema de cultivo em vasos & Aspectos negativos? \\
\hline \multirow{3}{*}{ Por sementes } & Principais características? \\
\cline { 2 - 2 } & Aspectos positivos? \\
\cline { 2 - 2 } & Aspectos negativos? \\
\hline \multirow{2}{*}{ Por estacas } & Principais características? \\
\cline { 2 - 2 } & Aspectos positivos? \\
\cline { 2 - 2 } & Aspectos negativos? \\
& \\
\hline
\end{tabular}

Entretanto, em muitos casos, os produtores não informaram gastos com luz e água, tendo a produção de espécies do gênero Thuja pesquisadas não necessitam de equipamentos e máquinas que consomem energia elétrica. Os gastos com água foram excluídos dos custos variáveis, já que o consumo da água para a produção das mudas nos viveiros avaliados era proveniente de nascentes, rios, arroios ou sangas localizadas dentro da propriedade de pequenos agricultores, os quais se constituem no principal grupo de produtores. 


\section{RESULTADOS E DISCUSSÃO}

\section{Sistema de cultivo a campo por semente e por estacas}

O cultivo de tuias exige ar bastante úmido, muito sol e um solo bem drenado, além de não ser essencial que se apliquem fertilizante, embora a adubação possa acelerar o seu lento crescimento. Com quatro anos de idade os indivíduos atingem cerca de 1,2 $\mathrm{m}$ de altura em sistemas de cultivo que não utilizam adubação. A mesma taxa de desenvolvimento pode ser obtida um ano antes com a aplicação de adubação básica de fósforo, potássio, nitrogênio e uréia, além de esterco. O uso de herbicidas também pode corroborar para um melhor desenvolvimento dos indivíduos, tendo em vista que controla as plantas invasoras em plantios extensivos e diminui a mato-competição.

O processo de plantio por sementes consiste na escolha de sementes de boa qualidade e no plantio destas, dependendo da coleta de sementes de árvores matrizes, selecionadas a partir dos indivíduos que apresentam maior vigor. Semeiam-se as sementes em sacos de plástico, ou diretamente a campo, as quais germinam depois de quatro a cinco semanas, produzindo um broto com duas pequenas folhas em forma de agulha. Entre 8 e 12 meses as mudas são transplantadas para o campo, sendo plantadas no solo com espaçamento de $0,7 \times 1 \mathrm{~m}$ a sol pelo, entretanto, devem ser protegidas do sol de verão, pois os verões muito quentes e secos ressecam as mudas, inviabilizando sua comercialização.

O processo de estaquia consiste na escolha de árvores sadias para o fornecimento de galhos, dos quais são retiradas as estacas, que devem ser enterradas em lugar sombreado e úmido com $1 \mathrm{~m}$ metro de distância entre indivíduos, em ambiente protegido por tela, controlando-se as condições fitossanitárias exigidas para a atividade. Quando as mudas são produzidas por estacas, dá-se preferência para a coleta de ramos novos, que permitem um melhor desenvolvimento. Estacas de 10 a $15 \mathrm{~cm}$ são enterradas em recipientes contendo substrato de areia grossa ou casca de arroz carbonizada, a qual é preferida para a maioria dos produtores. Após a rustificação das mudas, as mesmas são transplantadas para o campo.

Um hormônio presente nas plantas da espécie Thuja occidentalis faz com que as estacas lancem raízes no período de dois a três meses, ao contrário das plantas da espécie Thuja orientalis, que apresentam maior dificuldade de lançar raízes. As mudas são regadas tanto durante o desenvolvimento no viveiro quanto nas primeiras semanas após o transplante para o campo, que ocorre com cerca de um ano de vida.

Percebeu-se que a maioria dos produtores prefere realizar a multiplicação de Thuja occidentalis por estacas, devido à dificuldade que esta espécie apresenta na produção de sementes no Brasil. Já para a Thuja orientalis, prefere-se a multiplicação por sementes, pois 
este método de propagação permite formar mudas com copa conformada e compacta, o que é essencial na hora de oferecer o produto.

Quanto à taxa de crescimento, as mudas de Thuja produzidas a partir de sementes desenvolvem-se mais rápido, sendo capazes de germinar em um período de três a quatro semanas, enquanto mudas produzidas por estacas levam de dois a três meses para emitir raízes. Tanto para a propagação por estacas como por sementes, as mudas cultivadas a campo (Figura 1) permanecem de dois a quatro anos, quando são transplantadas para vasos alguns meses antes de serem comercializadas.

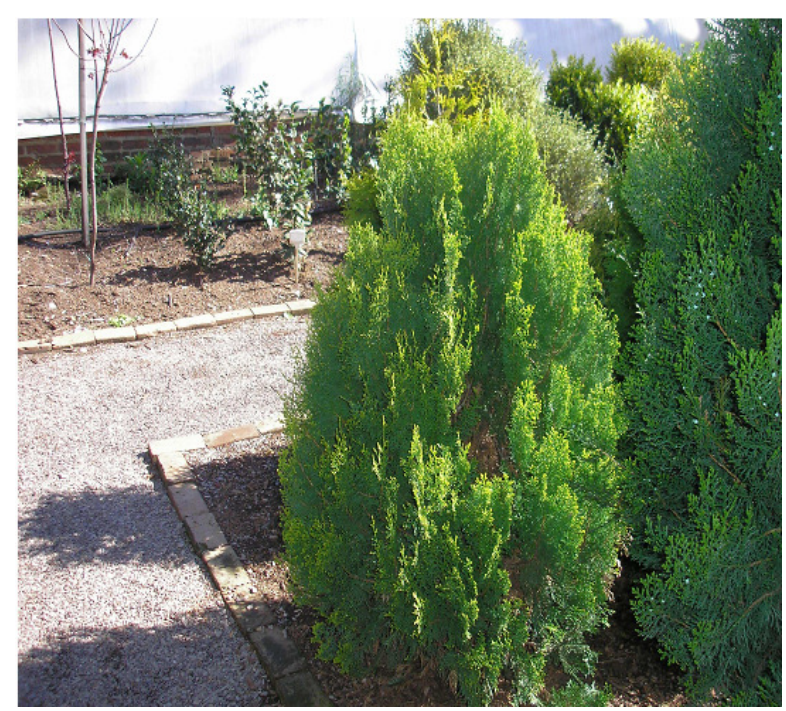

Figura 1. Aspecto do cultivo a campo de Thuja occidentalis.

\section{Sistema de cultivo em vasos por semente e por estacas}

No cultivo em vasos (Figura 2), tanto para a propagação por sementes como para estacas, as mudas são cultivadas em sacos de plástico, sendo transplantadas em vasos nos quais são vendidas, mas também podem ser cultivadas diretamente no vaso em que serão vendidas, desde que o vaso seja compatível com o porte desejado para venda.

Este sistema exige um pouco mais de experiência, pois o desenvolvimento das raízes deve ser monitorado para que não haja enovelamento. Deve-se escolher o tamanho do vaso adequado com o porte das mudas e sistema radicular, realizando-se, quando necessário, o transplante para vasos maiores. 


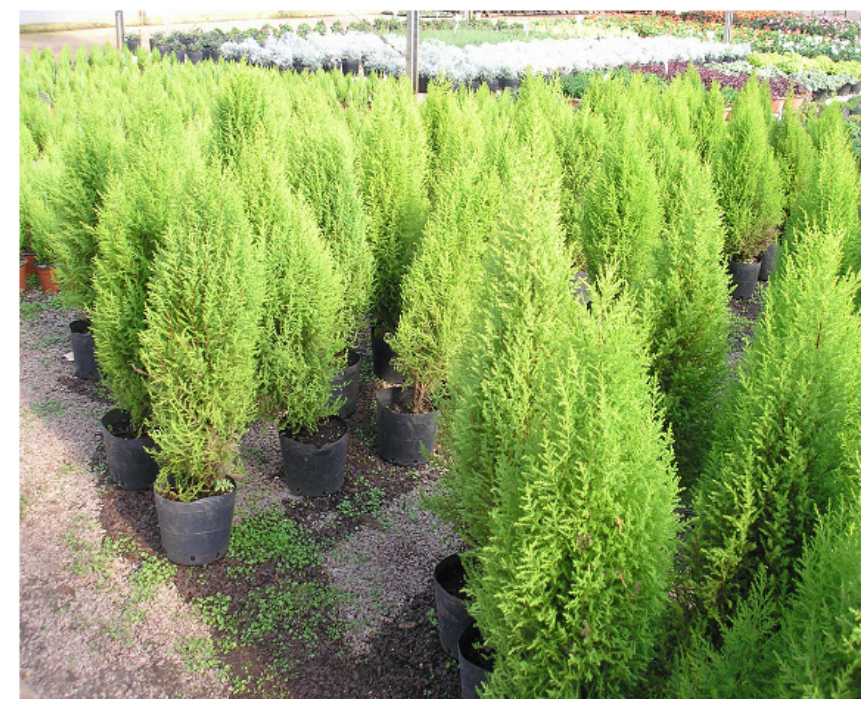

Figura 2. Sistema de cultivo de tuias em vasos.

Esse sistema mostra-se vantajoso pelo fato de reduzir o estresse provocado às mudas devido ao transplante do solo para o vaso, o que ocasiona perdas de mudas ou compromete seu aspecto estético.

Quanto à sobrevivência destas espécies, foram obtidas poucas informações, não sendo possível determinar exatamente a taxa de sobrevivência para cada espécie nos diferentes sistemas de cultivo. Todavia, foi possível diagnosticar que a Thuja orientalis se reproduz muito bem por sementes e que raramente há perda de mudas, principalmente quando cultivadas diretamente em vasos. Já, para Thuja occidentalis, a sobrevivência dos indivíduos é maior quando propagados por estacas e depois transplantadas para o campo.

\section{Custos de produção}

Os custos de produção foram calculados com base nos materiais mínimos necessários para a produção de Thuja; consideraram-se também os materiais mais citados pelos produtores. Os custos fixos e variáveis para a propagação por sementes encontramse nas Tabelas 2 e 3.

O custo total da muda de até um ano, produzida por sementes, ficou em $R \$ 2,77$, mas este custo pode ser bem maior, dependendo de outros insumos utilizados na produção. Alguns produtores utilizam também carvão na mistura de substrato, adubação com humos, uréia e casca de acácia, entre outros materiais orgânicos. No entanto, o objetivo da maioria dos produtores é tentar baixar os custos de produção a fim de que suas mudas possam ter preço mais competitivo no mercado gaúcho, principalmente devido à comercialização de mudas provenientes dos Estados de Santa Catarina e Paraná; para isso, buscam constantemente utilizar o material disponível na propriedade, caracterizando a produção de tuias no Estado do Rio Grande do Sul como pouco comercial e mais artesanal e familiar. 
Tabela 2. Custos fixos para produção de 1.000 mudas de Thuja a partir de semente.

\begin{tabular}{lcc}
\hline \multicolumn{1}{c}{ Implementos } & Quantidade & Custo Total (R\$) \\
\hline Ancinho & 1 und. & 3,48 \\
Carrinho-de-mão & 1 und. & 134,00 \\
Tesoura de poda & 1 und. & 28,00 \\
Enxada & 1 und. & 7,88 \\
Pá de corte & 1 und. & 6,30 \\
Sombrite (30\%) & $80 \mathrm{~m}^{2}$ & 186,30 \\
Mangueira plástica(100m) & 1 und. & 20,00 \\
Balde (20L) & 2 und. & 7,00 \\
Regador & 2 und. & 6,00 \\
\hline Total & & $\mathbf{3 9 8 , 9 6}$ \\
\hline Total/muda & & $\mathbf{0 , 4 0}$ \\
\hline
\end{tabular}

Tabela 3. Custos variáveis para produção de 1.000 mudas de Thuja a partir de semente.

\begin{tabular}{lcr}
\hline \multicolumn{1}{c}{ Implementos } & Quantidade & Custo Total (R\$) \\
\hline Sacos de plástico & $1.000 \mathrm{und}$. & 53,00 \\
Adubo orgânico & $1.000 \mathrm{~kg}$ & 200,00 \\
Adubo N-P-K & $150 \mathrm{~kg}$ & 112,50 \\
Casca de arroz & $1 \mathrm{~m}^{3}$ & 1,20 \\
Areia & $1 \mathrm{~m}^{3}$ & 28,75 \\
Mão-de-obra & 1 viveirista & 432,55 \\
Vaso & 1.000 und. & $1.500,00$ \\
Fungicida sistêmico & $1 \mathrm{~L}$ & 50,00 \\
\hline Total & & $\mathbf{2 . 3 7 8 , 0 0}$ \\
\hline Total/muda & & $\mathbf{2 , 3 7}$ \\
\hline
\end{tabular}

Já os custos com água não foram incluídos porque, os produtores não possuem um controle de quantos litros consomem para a irrigação da produção de tuia, ou então, a água provém de fonte natural existente dentro da propriedade.

Os custos fixos e variáveis para a propagação por estacas encontram-se nas Tabelas 4 e 5 . O custo total por muda propagada por estaquia ficou em $R \$ 2,79$, para mudas de até um ano de idade, representando um custo adicional de $R \$ 0,02$ por muda em 
relação às propagadas por semente. Neste caso, vale ressaltar que este custo também depende da variação dos insumos utilizados no plantio, como comentado para o custo de produção por semente.

Entre os dois sistemas de cultivo, em vasos ou a campo, o sistema que apresenta o custo de produção mais reduzido, é o cultivo a campo, pelo fato da muda permanecer em um local mais livre, recebendo os nutrientes do solo, iluminação, ar, além de reaproveitar a água das chuvas, exigindo, assim, menos cuidados especiais.

Tabela 4. Custos fixos para produção de 1.000 mudas de Thuja a partir de estacas.

\begin{tabular}{lcc}
\hline \multicolumn{1}{c}{ Implementos } & Quantidade & Custo Total (R\$) \\
\hline Carrinho-de-mão & 1 und. & 134,00 \\
Tesoura de poda & 1 und. & 28,00 \\
Enxada & 1 und. & 7,88 \\
Pá de corte & 1 und. & 6,30 \\
Sombrite (30\%) & $80 \mathrm{~m}^{2}$ & 186,30 \\
Mangueira plástica $(100 \mathrm{~m})$ & 1 und. & 20,00 \\
Balde (20L) & 2 und. & 7,00 \\
Regador & 2 und. & 6,00 \\
\hline Total & & $\mathbf{3 9 8 , 9 6}$ \\
\hline Total/muda & & $\mathbf{0 , 4 0}$
\end{tabular}

Tabela 5. Custos variáveis para produção de 1.000 mudas de Thuja a partir de estacas.

\begin{tabular}{lcr}
\hline \multicolumn{1}{c}{ Implementos } & Quantidade & Custo Total (R\$) \\
\hline Sacos de plástico & $1.000 \mathrm{und}$. & 53,00 \\
Adubo orgânico & $1.000 \mathrm{~kg}$ & 200,00 \\
Adubo N-P-K & $150 \mathrm{~kg}$ & 112,50 \\
Casca de arroz & $1 \mathrm{~m}^{3}$ & 1,20 \\
Areia & $1 \mathrm{~m}^{3}$ & 28,75 \\
Mão-de-obra & 1 viveirista & 432,55 \\
Água sanitária & 5 und. & 9,00 \\
Vaso & 1.000 und. & $1.500,00$ \\
Fungicida sistêmico & $1 \mathrm{~L}$ & 50,00 \\
\hline Total & & $\mathbf{2 . 3 8 7 , 0 0}$ \\
\hline Total/muda & & $\mathbf{2 , 3 9}$ \\
\hline
\end{tabular}


Os custos encontrados na pesquisa estão próximos dos custos de produção citados pelos produtores, os quais atingem de $R \$ 2,00$ a $R \$ 3,00$ por muda produzida.

Para termos uma idéia mais concreta dos preços de tuias comercializadas, resolvemos compará-los, de acordo com os diferentes portes das mudas. Verifica-se que o produtor pode obter um lucro de $R \$ 2,21$, caso comercialize a muda com porte de 30 a $50 \mathrm{~cm}$ (Tabela 6).

Tabela 6. Porte das tuias comercializadas e seus respectivos preços.

\begin{tabular}{lc}
\hline Portes & Preços no comércio (R\$) \\
\hline $30 \mathrm{~cm}-50 \mathrm{~cm}$ & $3,00-5,00$ \\
$50 \mathrm{~cm}-80 \mathrm{~cm}$ & $5,00-12,00$ \\
$80 \mathrm{~cm}$ & $12,00-18,00$ \\
$1-2 \mathrm{~m}$ & $10,00-20,00$ \\
$2-3 \mathrm{~m}$ & 90,00 \\
$>3 \mathrm{~m}$ & 250,00 \\
\hline
\end{tabular}

\section{CONCLUSÕES}

Pelos dados obtidos e analisados, conclui-se que:

- não existe diferença significativa de custos nos sistemas de produção de tuia estudados, mas existe diferença de custos para a idade em que a muda é comercializada;

- a taxa de desenvolvimento das mudas nos sistemas propagados por semente tem sido maior no que nos sistemas propagados por estacas;

- para a taxa de sobrevivência, os dados permitiram concluir, apenas, que as mudas de Thuja occidentalis apresentam maior sobrevivência quando propagadas por estacas e cultivadas a campo, enquanto mudas de Thuja orientalis apresentam maior sobrevivência quando propagadas por sementes e em vasos;

- mudas produzidas por semente e em sistemas de cultivo em vasos apresentam melhores características estéticas.

\section{REFERÊNCIAS}

CARNEIRO, J.G.A. Produção e controle de qualidade de mudas florestais. Curitiba:UFPR, 1995. 451p. 
GLASS, V. Tradição. São Paulo: Globo Rural, Ed Globo, 2001. Disponível em: <http://globorural.globo.com/barra.asp?d=/edic/194/rep_natala.htm>. Acesso em: 17 de fev. 2006.

GREY, G.W.; DENEKE, F.J. Urban forestry. New York: John Wiley, 1978. 279p.

LORENZI, H., et al. Árvores exóticas no Brasil: madeireiras, ornamentais e aromáticas. Nova Odessa, SP: Instituto Plantarum de Estudos Florestais, 2003. p.40 - 41.

MACEDO, A.C. Produção de mudas em viveiros florestais: espécies nativas. São Paulo: Fundação Florestal, 1993. 17p.

MARCHIORI, J.N.C. Dendrologia das gimnospermas. Santa Maria: Ed. UFSM, 1996. p.80, p.86-87.

MARTINS, R.C.C.; JACINTO, J.M.M.; MARTINS, I.S. Viveiros florestais. Brasília: Universidade de Brasília, 1998. 22p.

MILLER, W.R. Urban forestry - planning and managing urban greenspaces. 2.ed. New Jersey: Prentice-Hall, 1997. 502 p.

SANTOS, N.R.Z.; TEIXEIRA, I.F. Arborização de vias públicas: Ambiente x Vegetação. Porto Alegre: Ed. Pallotti, 2001. p.1-18. 